\title{
Atorvastatin inhibits osteoclastogenesis by decreasing the expression of RANKL in the synoviocytes of rheumatoid arthritis
}

\author{
Jeong Yeon $\mathrm{Kim}^{1 \dagger}$, Eun Young Lee ${ }^{1 \dagger}$, Eun Bong Lee ${ }^{1}$, Yun Jong Lee ${ }^{2}$, Hyun Jung Yoo ${ }^{1}$, Jiyong Choi ${ }^{1}$ and \\ Yeong Wook Song ${ }^{1,3^{*}}$
}

\begin{abstract}
Introduction: Statins, hydroxymethylglutaryl-coenzyme A reductase inhibitors, have been reported to have antiinflammatory and/or immunomodulatory effects and prophylactic and therapeutic effects in collagen-induced arthritis, an experimental model of rheumatoid arthritis (RA). The authors undertook to determine the effect of atorvastatin on the expressions of osteoprotegerin (OPG) and receptor activator of nuclear factor $\kappa \mathrm{B}$ ligand (RANKL) in RA fibroblast-like synoviocytes (FLSs), to identify the mechanisms responsible for these effects, and to determine whether the statin inhibits osteoclastogenesis.
\end{abstract}

Methods: FLSs isolated from five RA patients were cultured in the presence of $20 \mathrm{ng} / \mathrm{ml}$ of tumor necrosis factor- $\alpha$ (TNF- $\alpha$ ) with or without atorvastatin. RANKL expressions were assayed with Western blotting and enzyme-linked immunosorbent assay. RANKL, RANK, and OPG expression were assayed with reverse transcription-polymerase chain reaction (RT-PCR). Osteoclast formation was assayed by counting cells after staining for tartrate-resistant acid phosphatase in cocultures of peripheral blood mononuclear cells (PBMCs) and RA FLSs.

Results: Atorvastatin inhibited the expression of RANKL in RA FLSs in a dose-dependent manner, and the suppression of RANKL was prevented by mevalonate. However, OPG expression was not affected by atorvastatin in RA FLSs, and atorvastatin did not affect RANK expression in CD14 ${ }^{+}$cells. Conversely, atorvastatin suppressed TNF- $\alpha-$ induced p38 phosphorylation in RA FLSs and significantly reduced TRAP-positive multinucleated osteoclast formation in the coculture of PBMCS and RA FLSs.

Conclusion: These results suggest that atorvastatin inhibits osteoclastogenesis and bone destruction in RA patients.

\section{Introduction}

Receptor activator of nuclear factor $\kappa \mathrm{B}$ ligand (RANKL), and its receptor, RANK, have been found to be key factors in the stimulation of osteoclast formation, and they have also been suggested to play major roles in inflammationinduced bone loss and joint destruction in arthritis [1,2]. The soluble tumor necrosis factor (TNF)-receptor molecule, osteoprotegerin (OPG), is a natural inhibitor of RANKL. OPG binds to RANKL and prevents it from interacting with RANK, and thus, the balance between

\footnotetext{
* Correspondence: ysong@snu.ac.kr

+ Contributed equally

'Division of Rheumatology, Department of Internal Medicine, Seoul National University Hospital, 101 Daehak-ro, Jongno-gu, Seoul, 110-744, Korea

Full list of author information is available at the end of the article
}

RANKL and OPG in the bone microenvironment regulates bone resorption [3].

Rheumatoid arthritis (RA) is characterized by inflammatory synovitis and progressive destruction of joint cartilage and bone $[4,5]$. Furthermore, RA patients exhibit high serum levels of OPG and soluble RANKL [6]; RANKL mRNA is present in the synovial lining layer in RA [7]. However, RANKL is not expressed in normal synovium, which suggests a link between RANKL expression and the development of synovial lesions in RA [8]. In addition, recent studies provided genetic evidence that RANKL and osteoclasts are central players in the inflammatory destruction of bone [9] and that enhanced

\section{() Biomed Central}

(c) 2012 Kim et al.; licensee BioMed Central Ltd. This is an open access article distributed under the terms of the Creative Commons Attribution License (http://creativecommons.org/licenses/by/2.0), which permits unrestricted use, distribution, and reproduction in any medium, provided the original work is properly cited. 
RANKL expression in synoviocytes induced by synovial inflammation may be critical for osteoclastogenesis [10].

Statins, hydroxymethylglutaryl-coenzyme A (HMG$\mathrm{CoA}$ ) reductase inhibitors, constitute a family of chemically related molecules with lipid-lowering effects. Statins are extensively used in medical practice, and large-scale clinical trials have demonstrated their efficacies at reducing cardiovascular-related morbidities and mortalities $[11,12]$. Furthermore, increasing clinical and experimental evidence indicates that statins might have general antiinflammatory and immunomodulatory effects; research studies conducted over the last 10 years have elucidated a number of mechanisms by which statins may exert antiinflammatory effects $[13,14]$. More recently, the beneficial effects of statins have been extended to the direct immunomodulation of monocyte-mediated inflammatory processes (including chronic inflammatory diseases, such as atherogenesis and RA), independent of their effects on cholesterol levels [15-17].

Atorvastatin has been shown to have antiinflammatory potential in RA clinical trials $[18,19]$. However, the effects of atorvastatin on human osteoclasts have not been determined. In this study, we examined the effects of atorvastatin on the expressions of OPG and RANKL in fibroblast-like synoviocytes (FLSs) from RA patients and the mechanisms involved, and in addition, we sought to determine whether the statin inhibits osteoclastogenesis.

\section{Materials and methods Chemicals}

Atorvastatin (Pfizer, New York, NY, USA) was prepared as a suspension in dimethyl sulfoxide (DMSO; Sigma, St. Louis, MO, USA). Mevalonate (Sigma) was dissolved in $1 \mathrm{~N} \mathrm{NaOH}$ (pH 7.1). SB2035820, p38 inhibitor, was purchased from Cell Signaling Technology (Danvers, MA, USA).

\section{Primary culture of FLS}

Synovial tissues were obtained from five patients undergoing joint-replacement surgery. All five patients fulfilled the 2010 rheumatoid arthritis classification criteria of RA by the American College of Rheumatology/European League Against Rheumatism collaborative initiative [20]. This study was approved by the Institutional Review Board, and informed consent was obtained from all patients. Their clinical characteristics are shown in Table 1.

Synovial tissues were washed with phosphate-buffered saline (PBS), minced, and digested for 2 hours at $37^{\circ} \mathrm{C}$ in Dulbecco Modified Eagle's Medium-High Glucose (DMEM-HG; JBI, Daejeon, Korea) containing $1 \mathrm{mg} / \mathrm{ml}$ type II collagenase (Worthington Biochemical Corporation, NJ, USA). The digested tissues were filtered through a 70- $\mu \mathrm{m}$ cell strainer (Becton Dickinson, Franklin Lakes, NJ, USA). Cell suspensions were centrifuged at 1,400 rpm for 20 minutes at room temperature, and cell pellets were resuspended in DMEM-HG containing 1\% penicillin-streptomycin (Gibco/BRL, Grand Island, NY, USA) and 10\% heat-inactivated fetal bovine serum (FBS; Gibco/ BRL). The cells were then plated in $100-\mathrm{mm}$ culture dishes (Becton Dickinson) and incubated in a humidified $5 \% \mathrm{CO}_{2}$ atmosphere. On reaching confluence, cells were detached with $0.1 \%$ trypsin-EDTA (Gibco/BRL) and split into $5 \times 10^{5}$ cells per dish. For all experiments, three- to five-passage synovial fibroblasts were used.

\section{Immunomagnetic selection of $\mathrm{CD}^{+} 4^{+}$cells}

CD $14^{+}$cells were purified by MACS according to the manufacturer's instructions (Miltenyi Biotech, Auburn, CA, USA). In brief, $10^{7} \mathrm{PBMCs}$ were resuspended in $80 \mu \mathrm{l}$ of cold PBS containing $0.5 \%$ BSA and $2 \mathrm{~m} M$ EDTA (MACS buffer). Microbeads $(20 \mu \mathrm{l})$ conjugated with mouse anti-human CD14IgG2a (Miltenyi Biotech) were then added to cells and incubated for 15 minutes at $4^{\circ} \mathrm{C}$. Cells were then washed and resuspended in $3 \mathrm{ml}$ of MACS buffer and then applied to a preequilibrated sterile LS separation column (Miltenyi Biotech) placed in a MidiMACS magnet. The column was then washed 3 times with MACS buffer, and CD14 ${ }^{+}$cells were eluted with $5 \mathrm{ml}$ of MACS buffer after removing the column from the magnet.

\section{Methylthiazol tetrazolium assay}

FLSs or PBMCs were cultured to confluence in 96-well plates (Becton Dickinson) and treated with M-CSF (2 ng/ml), 1,25-dihydroxyvitamin $\mathrm{D}_{3}\left(10^{-7} \mathrm{M}\right)$, atorvastatin for 24 hours $(10$ to $100 \mu M)$ or 3 weeks $(0.001$ to $0.1 \mu M)$ in a $5 \% \mathrm{CO}_{2}$ incubator. Methylthiazol tetrazolium (MTT) labeling reagent $(500 \mu \mathrm{g} / \mathrm{ml}$; Sigma) was added to FLSs or PBMCs in wells and incubated for 2 hours at $37^{\circ} \mathrm{C}$. Isopropanol supplemented with $0.4 \mathrm{M}$ $\mathrm{HCl}$ was then added to release formazan dye from cells. Formazan absorbance in solution was measured by using a microtiter-plate enzyme-linked immunosorbent assay (ELISA) reader at $570 \mathrm{~nm}$.

\section{Propidium iodide staining}

FLSs were cultured in 100-mm culture dishes and treated with TNF- $\alpha(20 \mathrm{ng} / \mathrm{ml})$ and atorvastatin $(10$ to $100 \mu M)$ for 24 hours. Cells were harvested by using $0.1 \%$ trypsinEDTA, washed twice in PBS containing 0.1\% (wt/vol) $\mathrm{NaN}_{3}$, and then $1 \mathrm{ml}$ of cold $70 \%$ (vol/vol) ethanol was added to cell pellets. Cells were then vortexed and incubated at $4^{\circ} \mathrm{C}$ for 1 hour, washed twice, and resuspended in $0.1 \mathrm{ml}$ of PBS containing $0.1 \% \mathrm{NaN}_{3}$. For DNA staining, cells were treated with $1 \mathrm{mg} / \mathrm{ml}$ of RNase A (Sigma), resuspended in $0.5 \mathrm{ml}$ of $\mathrm{PBS}$ containing $50 \mathrm{mg} / \mathrm{ml}$ 


\begin{tabular}{lllll}
\hline $\begin{array}{l}\text { Patient } \\
\begin{array}{l}\text { Disease } \\
\text { duration } \\
\text { (months) }\end{array}\end{array}$ & $\begin{array}{l}\text { Site of } \\
\text { surgery }\end{array}$ & Gender Medication \\
\hline $\mathbf{1}$ & 180 & Knee & Female & Prednisolone, $5 \mathrm{mg} / \mathrm{d}$; celecoxib, $200 \mathrm{mg} / \mathrm{d}$; gasmotine, $2.5 \mathrm{mg} / \mathrm{d}$ \\
$\mathbf{2}$ & 36 & Knee & Female & Cyclosporin A, $100 \mathrm{mg} / \mathrm{d}$; triamcinolone, $2 \mathrm{mg} / \mathrm{d}$ \\
$\mathbf{3}$ & 240 & Knee & Male & Prednisolone, $5 \mathrm{mg} / \mathrm{d}$; hydroxychloroquine, $200 \mathrm{mg} / \mathrm{d}$; sulfasalazine, $500 \mathrm{mg} / \mathrm{d}$ \\
$\mathbf{4}$ & 180 & Hip & Female & Hydroxychloroquine, $200 \mathrm{mg} / \mathrm{d}$ \\
$\mathbf{5}$ & 187 & Knee & Female & $\begin{array}{l}\text { Deflazacort, } 5 \mathrm{mg} / \mathrm{d} ; \text { methotrexate, } 12.5 \mathrm{mg} / \mathrm{wk} \text {; leflunomide, } 10 \text { mg/d; hydroxychloroquine, } \\
200 \mathrm{mg} / \mathrm{d}\end{array}$ \\
\hline
\end{tabular}

propidium iodide (PI; Sigma), and incubated for $30 \mathrm{~min}$ utes at $4^{\circ} \mathrm{C}$ in the dark. They were then analyzed with flow cytometry (FACS Caliber, BD Science), and the sub$\mathrm{G}_{0} / \mathrm{G}_{1}$ portion (the $\mathrm{M} 1$ fraction) was considered to be the apoptotic fraction.

\section{Reverse transcription-polymerase chain reaction and real- time real-time PCR}

Total RNA was extracted from FLSs or CD $14^{+}$cells by using TRIzol reagent (Invitrogen Life Technologies, Carlsbad, CA, USA) according to the manufacturer's instructions. In brief, FLSs or CD $14^{+}$cells were cultured in six-well plates in the presence or absence of TNF- $\alpha$ $(20 \mathrm{ng} / \mathrm{ml})$, atorvastatin for FLSs $(10$ to $100 \mu \mathrm{M})$, for CD $14^{+}$cells $(0.01$ to $1 \mu M)$ for 24 to 72 hours. The cells were then lysed by adding $1 \mathrm{ml}$ TRIzol reagent, and lysates were collected in $1.5-\mathrm{ml}$ microtubes, to which was added $0.2 \mathrm{ml}$ of chloroform (Sigma). The microtubes were then centrifuged at $12,000 \mathrm{~g}$ for 15 minutes at $4^{\circ} \mathrm{C}$, and supernatants were transferred to new microtubes. Isopropyl alcohol $(0.5 \mathrm{ml})$ was then added to precipitate RNA, and microtubes were centrifuged at 12,000 $\mathrm{g}$ for 8 minutes at $4{ }^{\circ} \mathrm{C}$. Pellets were washed with $75 \%$ ethanol, dried at room temperature, and resuspended in 10 to $20 \mu \mathrm{l}$ nuclease-free water (Applied Biosystems/Ambion, Austin, TX, USA). RNA concentrations were determined by measuring absorbance at $260 \mathrm{~nm}$.

First-strand cDNA was synthesized by using a Power cDNA Synthesis Kit (Intron Biotechnology, Seongnam, South Korea). The reaction was conducted in $20 \mu \mathrm{l}$ of buffer containing $1 \mu \mathrm{g}$ of total RNA, $0.2 \mathrm{~m} M$ oligo $(\mathrm{dT})_{15}$ primer, $5 \times$ RT buffer, $40 \mathrm{mM}$ DTT, 10 units of RNase inhibitor, $2.5 \mathrm{~m} M$ deoxynucleotide triphosphate (dNTP) mixture, and 5 units of AMV reverse transcriptase. After incubation at $37^{\circ} \mathrm{C}$ for 1 hour, the reaction was stopped by heating at $70^{\circ} \mathrm{C}$ for 15 minutes. To remove the remaining RNA, $1 \mu \mathrm{l}$ of Escherichia coli RNase H $(4 \mathrm{mg} / \mathrm{ml})$ was added to reaction mixtures and this was followed by incubation at $37^{\circ} \mathrm{C}$ for 30 minutes. The housekeeping gene, glyceraldehyde 3-phosphate dehydrogenase (GAPDH), was used as an internal control for determining gene expression. The primers used to detect RANKL (S, 5' GCC AGT GGG AGA TGT TAG 3'; AS, 5' TTA GCT GCA AGT
TTT CCC 3'); RANK (S, 5' TTA AGC CAG TGC TTC ACG GG 3'; AS, 5’ ACG TAG ACC ACG ATG ATG TCG C 3'); OPG (S, 5' TGC TGT TCC TAC AAA GTT TAC C 3'; AS, 5' CTT TGA GTG CTT TAG TGC GTG 3'), and GAPDH (S, 5' GCT CTC CAG AAC ATC ATC CC 3'; AS, 5' CGT TGT CAT ACC AGG AAA TG 3').

PCR amplification of CDNA was performed in an automated thermal cycler (GeneAmp PCR System 2400, Applied Biosystems) in a final volume of $20 \mu$ l containing 1 to $4 \mu \mathrm{l}$ of cDNA, $20 \mathrm{mM}$ Tris- $\mathrm{HCl}(\mathrm{pH} 8.4), 50 \mathrm{mM}$ $\mathrm{KCl}, 1.5 \mathrm{mM} \mathrm{MgCl} 2,0.1 \%$ Triton X-100, $0.2 \mathrm{mM}$ dNTP mixture, 0.5 pmol of each primer, and 5 units of Taq DNA polymerase (Promega). After PCR, the amplified products were analyzed with electrophoresis in $1.5 \%$ agarose gel and visualized with ethidium bromide staining under UV illumination. Band intensities of PCR products were measured by using a UV/VIS Vilber Lourmat digital camera and the software BioCaptMW (Vilber Lourmat, Marne-la-Vallée, France).

Real-time PCR was performed with the ABI 7500 realtime PCR system (Applied Biosystems). Total RNA was extracted by using an RNeasy kit (Qiagen, Valencia, CA, USA). Synthesis of cDNA was performed by using an SuperScript III First-Strand Synthesis System (Invitrogen) according to the manufacturer's protocol. Quantitative real-time PCR was performed by running a QuantiTect SYBR Green PCR Kit (Qiagen). Primer sequences were as follows; GAPDH, forward: CAATGACCCCTTCATTGACC; GAPDH, reverse: TGGACTCCACGACGTAC TCA; and RANKL, forward GCTTGAAGCTCAGCCT TTTG:; and RANKL, reverse: CGAAAGCAAATGTTGGCATA. The reactions were incubated at $94^{\circ} \mathrm{C}$ for $15 \mathrm{~min}$ utes for one cycle, and then at $94^{\circ} \mathrm{C}$ ( 15 seconds), $59^{\circ} \mathrm{C}$ (30 seconds), and $72^{\circ} \mathrm{C}$ (30 seconds) for 40 cycles. The quantity of mRNA was calculated by using the threshold cycle $\left(C_{t}\right)$ value for amplification of human RANKL and for human GAPDH as a reference gene. Relative gene expression was determined by the $2^{\Delta \Delta \mathrm{Ct}}$ method.

\section{Western blot analysis}

Protein expressions were measured with Western blotting. In brief, cells were washed twice with ice-cold PBS, scraped into microfuge tubes, pelleted by centrifugation, 
and suspended in PRO-PREP protein-extraction buffer (Intron). After 30 minutes of incubation on ice, samples were centrifuged at $14,000 \mathrm{rpm}$ for 30 minutes at $4^{\circ} \mathrm{C}$. Protein concentrations were measured by using Bio-Rad Protein Assay reagent (Bio-Rad) with bovine serum albumin as a standard. Sodium dodecylsulfate-polyacrylamide gel electrophoresis (SDS-PAGE) was carried out by using a mini-protein system (Bio-Rad). Dissolved protein samples were combined with sample buffer $(125 \mathrm{~m} M$ Tris (pH 6.8), 5\% glycerol, $2 \%$ SDS, $1 \% 2$-mercaptoethanol, and $0.006 \%$ bromophenol blue) boiled for 5 minutes, and immediately cooled. Equivalent amounts of protein samples $(50 \mu \mathrm{g} / \mathrm{lane})$ were loaded onto $12 \%$ SDS gels. Electrophoresis was carried out in a running buffer at $100 \mathrm{~V}$ for 2 hours. Proteins were transferred from gels onto polyvinylidene difluoride (PVDF) membranes (Millipore, Bedford, MA, USA; 90 minutes at $30 \mathrm{~V}$ ) in transfer buffer (192 mM glycine, $25 \mathrm{mM}$ Tris- $\mathrm{HCl}, \mathrm{pH}$ 8.3, 0.02\% SDS, and $20 \% \mathrm{vol} / \mathrm{vol}$ TBS-Tween buffer $(20 \mathrm{~m} M$ Tris, $\mathrm{pH} 8.0$, $150 \mathrm{mM} \mathrm{NaCl}$, and $0.1 \%$ Tween 20)) for 1 hour at $4^{\circ} \mathrm{C}$. After blocking with 5\% nonfat dried milk in TBS-Tween buffer for 1 hour, rabbit polyclonal antibody to human RANKL (R\&D), rabbit monoclonal anti-Akt/phospho-Akt, anti-ERK/phospho-ERK, anti-JNK/phospho-JNK, antip38/phospho-p38 antibodies (all from Cell Signaling Technology), and rabbit monoclonal anti-actin antibody (Sigma) were added and incubated for 12 hours. Membranes were then washed and incubated with HRP-conjugated goat anti-rabbit IgG polyclonal antibodies (1:1,000; Jackson Immunoresearch, Philadelphia, PA, USA). Chemiluminescent substrate (Amersham Life Science, Arlington Heights, IL, USA) was added, and incubation was continued for 10 minutes. Blots were then exposed to radiographic film.

\section{Enzyme-linked immunosorbent assay}

The secretion of sRANKL was detected by using RANKL ELISA kit (Peprotech), according to the manufacturer's directions.

\section{Coculture system for osteoclastogenesis}

Blood was collected from healthy volunteers, and PBMCs were isolated by centrifugation over Ficoll/ Paque at 1,700 rpm for 30 minutes. PBMCs were resuspended in $\alpha$-MEM containing $10 \%$ FBS and $2 \mathrm{ng} / \mathrm{ml}$ M-CSF (Sigma) and seeded at $2 \times 10^{5}$ cells/well in 96-well culture plates. On the following day, FLSs were added at $2 \times 10^{4}$ cells/well to adherent PBMCs and cocultured for 3 weeks in $\alpha$-MEM containing $10 \%$ FBS, $100 \mathrm{IU} / \mathrm{ml}$ benzyl penicillin, $100 \mathrm{mg} / \mathrm{ml}$ streptomycin, $2 \mathrm{ng} / \mathrm{ml} \mathrm{M-CSF}$, and $10^{-7} \mathrm{M}$ 1,25-dihydroxyvitamin $\mathrm{D}_{3}$. The culture medium was replaced every 3 days. Adherent cells were stained for tartrate-resistant acid phosphatase (TRAP) by using a commercially available kit
(Sigma), as previously described (10). TRAP-positive multinucleated cells containing three or more nuclei were identified as osteoclasts and counted with light microscopy. All experiments were carried out 3 times in triplicate.

\section{Statistical analysis}

Data are presented as mean \pm SD. Statistical analysis was performed by using SPSS version 12 (SPSS Inc., Chicago, IL, USA), and $P$ values of $<0.05$ were considered significant.

\section{Results}

Effects of atorvastatin on RANKL in the FLSs of RA patients

FLSs were cultured for 24 hours with atorvastatin in the presence of TNF- $\alpha(20 \mathrm{ng} / \mathrm{ml})$, and assayed for RANKL expression with RT-PCR and real-time PCR. Atorvastatin significantly and dose-dependently inhibited the expression of RANKL mRNA in the FLSs of RA patients $(P<$ 0.05) (Figure 1A, B). Western blotting of these cells showed that atorvastatin also dose-dependently suppressed RANKL protein levels (Figure 1C). Simvastatin has been reported to reduce arthritis incidence, activity, and histologic scores in a collagen-induced arthritis model, and simvastatin has been shown to have antiinflammatory potential in RA patients $(18,22)$. Therefore, we determined whether simvastatin inhibits the expression of RANKL. Simvastatin also significantly and dose-dependently

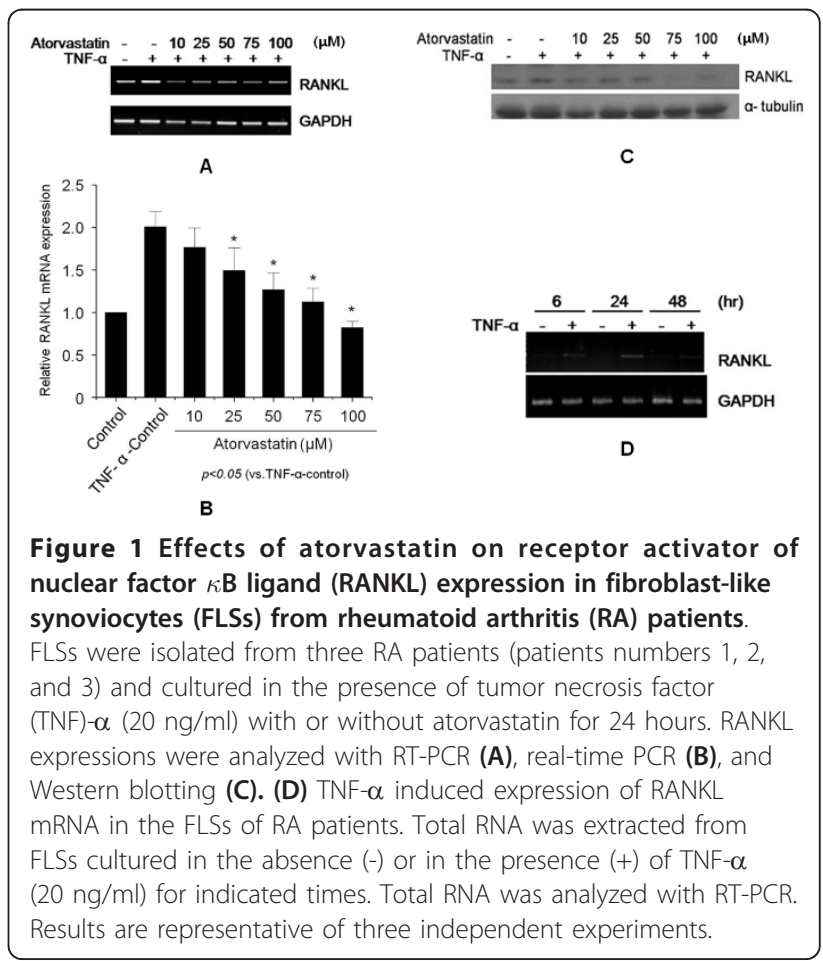


inhibited the expression of RANKL mRNA and protein in the FLSs of RA patients (see Additional file 1, Figure S1). To determine the most effective time for TNF- $\alpha$ stimulation, RANKL expression was analyzed with RT-PCR after treating the FLSs of RA patients for 24 to 48 hours with TNF- $\alpha$ (20 ng/ml). RANKL mRNA expression was found to peak after 24 hours of stimulation with TNF- $\alpha$ (20 ng/ml) (Figure 1D). Because mevalonate is synthesized from 3-hydroxy-3-methylglutaryl coenzyme A (HMGCoA) by HMG-CoA reductase, HMG-CoA reductase inhibitors, like statins, reduce the entry of mevalonate into the cholesterol synthesis pathway. To determine whether mevalonate prevents the inhibition of RANKL expression by atorvastatin, mevalonate $(100 \mu M)$ was cotreated with atorvastatin. RT-PCR and Western blotting showed that mevalonate prevented the suppression of RANKL expression by atorvastatin (Figure 2). Also, mevalonate prevented the inhibition of RANKL expression by simvastatin (see Additional file 2, Figure S2).

The effects of atorvastatin on cell viability and apoptosis The effect of atorvastatin on cell viability was determined by using an MTT-based assay (Figure 3A). Apoptosis was measured by staining with propidium iodide (Figure 3B). Neither cell viability nor apoptosis was affected by atorvastatin at concentrations of 10 to $100 \mu M$. Simvastatin did not affect cell viability and apoptosis (see Additional file 3, Figure S3).

Effects of atorvastatin on OPG in the FLSs of RA patients The expressions of OPG mRNA were examined in FLSs from patients cultured for 24 hours with RT-PCR.

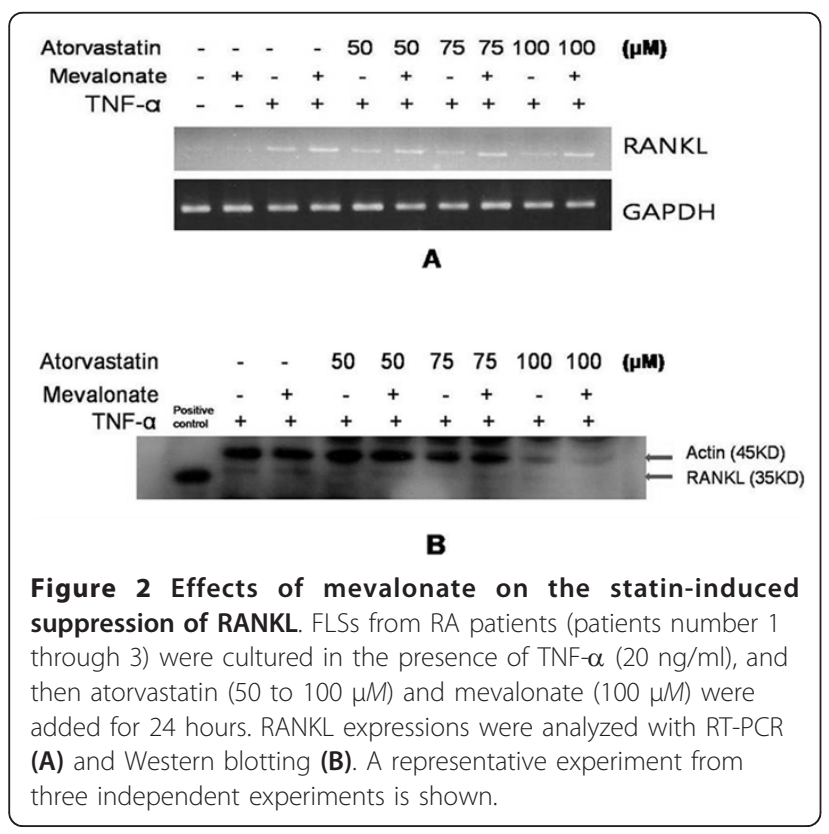

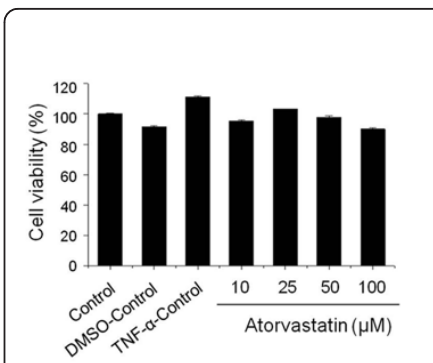

A

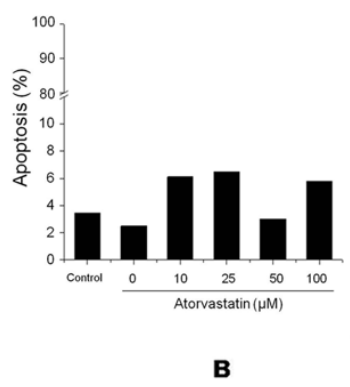

B
Figure 3 The effects of atorvastatin on cell viability and apoptosis. (A) Effects of atorvastatin on the viability of FLSs from an RA patient (patients 1, 2, and 3). Cells were cultured for 24 hours in the presence of TNF- $\alpha(20 \mathrm{ng} / \mathrm{ml})$ and atorvastatin at different concentrations (10 to $100 \mu \mathrm{M}$ ). Cell viabilities were determined by using MTT assays. (B) Effects of atorvastatin on the apoptosis of FLSs as determined by propidium iodide staining.

Atorvastatin did not affect OPG expression in these cells (Figure 4A). We also assayed the secretion of OPG into the conditioned media of FLSs cultured in the presence of atorvastatin, and the statin was found to affect OPG secretion (data not shown).

\section{Effect of atorvastatin on RANK in CD14 ${ }^{+}$cells}

The effect of atorvastatin on RANK in osteoclast precursor cells was evaluated by purifying $\mathrm{CD} 14^{+}$cells from total PBMCs by using a magnetic cell-separation (MACS) system. Atorvastatin did not affect RANK mRNA expression in CD14 ${ }^{+}$cells (Figure 4B), and the viabilities of $\mathrm{CD} 14^{+}$cells were not affected by atorvastatin at concentration up to $1 \mu M$ (Figure $4 \mathrm{C}$ ).

Effect of atorvastatin on tumor necrosis factor- $\alpha$-induced signal-transduction pathways in FLSs from rheumatoid arthritis patients

To investigate the mechanism by which atorvastatin suppresses the expression of TNF- $\alpha$-induced RANKL, we examined its effects on the phosphorylations of p38 MAPK, JNK, ERK, and Akt. Western blotting revealed that atorvastatin inhibited TNF- $\alpha$-induced p 38 phosphorylation after 12 hours, but that it did not affect the phosphorylations of JNK, ERK, and Akt (Figure 5A). When we pretreated cells with SB203580 (a p38 inhibitor), TNF- $\alpha$-induced RANKL mRNA expression was decreased, which was similar to the suppression of RANKL mRNA expression by atorvastatin (Figure 5B). We also measured soluble RANKL levels in FLSs culture media, and we found that its levels were decreased by SB203580 and by atorvastatin (Figure 5C).

\section{Inhibition of osteoclast formation}

It was reported that RANKL is produced by RA FLS. We added 1,25-dihydroxyvitamin $\mathrm{D}_{3}$ and M-CSF to 


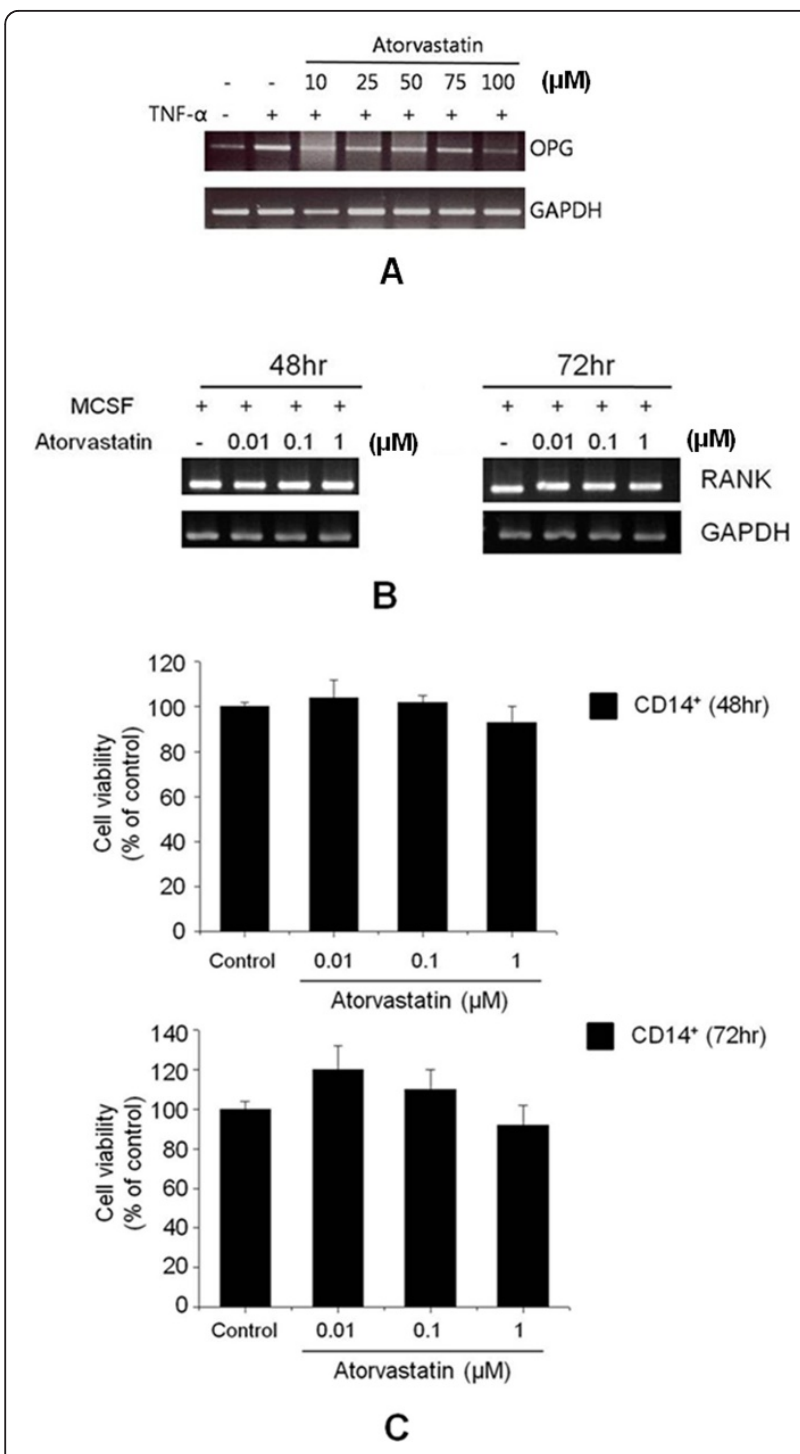

Figure 4 Effects of atorvastatin on osteoprotegerin (OPG) expression in FLSs and RANK expression in CD14 $4^{+}$cells of RA patients (patients 1, 4, and 5). (A) RT-PCR was used to analyze OPG mRNA expression in FLSs cultured for 24 hours with $20 \mathrm{ng} / \mathrm{ml}$ TNF- $\alpha$ and atorvastatin (10 to $100 \mu M$ ). The results shown are representative of three independent experiments. (B) CD14 ${ }^{+}$cells were cultured for 48 or 72 hours in the presence of $2 \mathrm{ng} / \mathrm{ml}$ of macrophage colony-stimulating factor and different concentrations of atorvastatin $(0.01$ to $1 \mu \mathrm{M})$. RANK mRNA expression was not affected by atorvastatin according to RT-PCR results. (C) Atorvastatin had no effect on the viability of $\mathrm{CD} 14^{+}$cells at concentrations up to $1 \mu \mathrm{M}$. The results are representative of three independent experiments.

media in which FLSs or cocultured cells were grown, according to a previously described method [3]. We could produce functionally active osteoclasts, and they were determined by TRAP staining (Figure 6A). When atorvastatin was added to cocultures of PBMCs and FLSs for 3 weeks, atorvastatin at $\geq 0.01 \mu M$ significantly

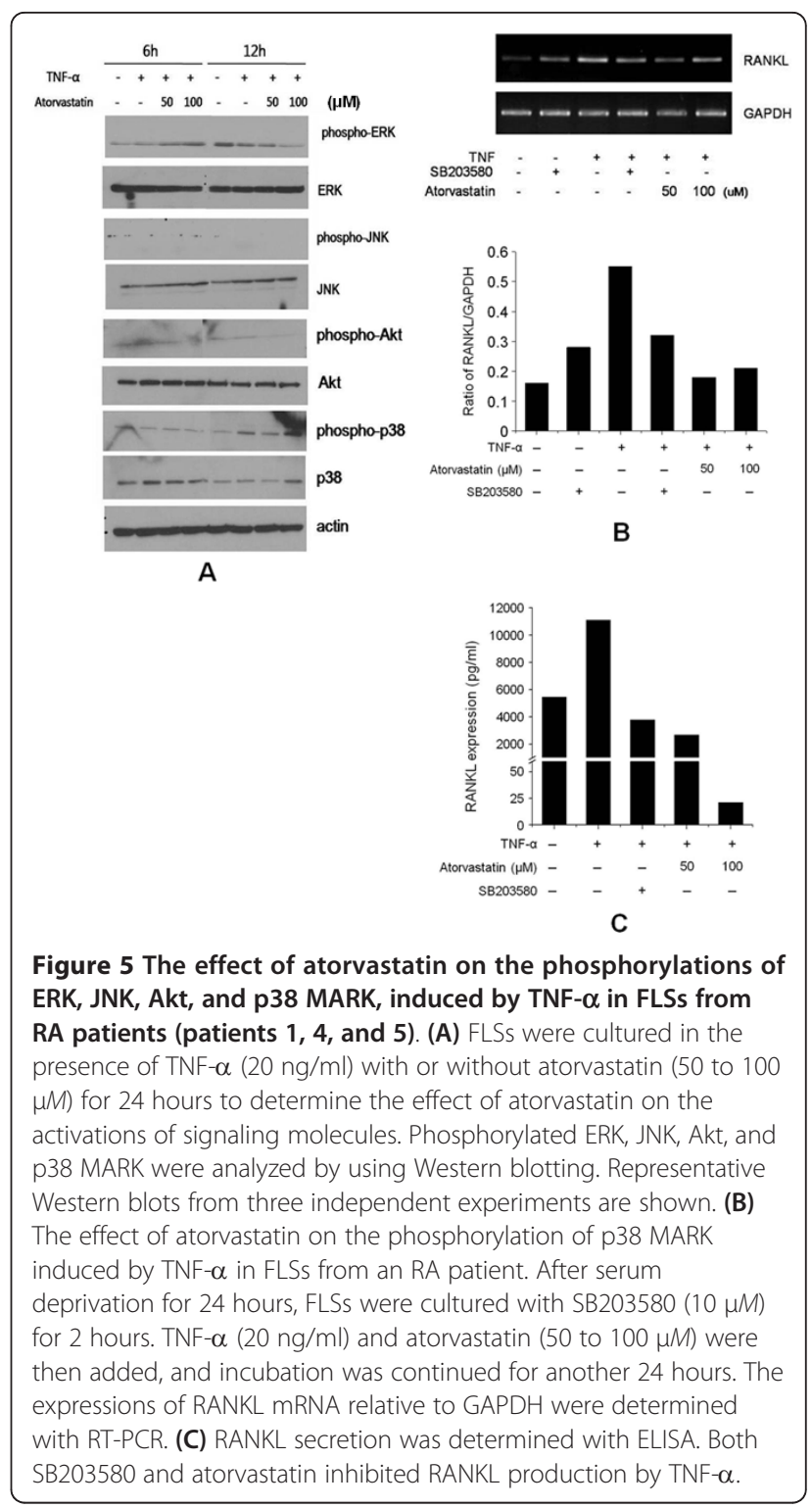

decreased the numbers of TRAP-positive multinucleated osteoclasts $(P<0.01$ versus control) (Figure 6A, B). To ensure that the inhibitory effect of atorvastatin on osteoclast formation was not due to an effect on cell viability, we performed MTT assay. Cell viabilities were assayed in separate cultures of FLSs and PBMCs. The viability of PBMCs after 3 weeks of treatment in the presence of M-CSF was not affected by atorvastatin (Figure 6C). Furthermore, atorvastatin had no effect on FLS viability after 3 weeks of treatment in the presence of vitamin $\mathrm{D}_{3}$ (Figure 6D).

\section{Discussion}

Statins inhibit the rate-limiting step of cholesterol synthesis by preventing HMG-CoA from being reduced to mevalonate by HMG-CoA reductase [21]. In addition, 


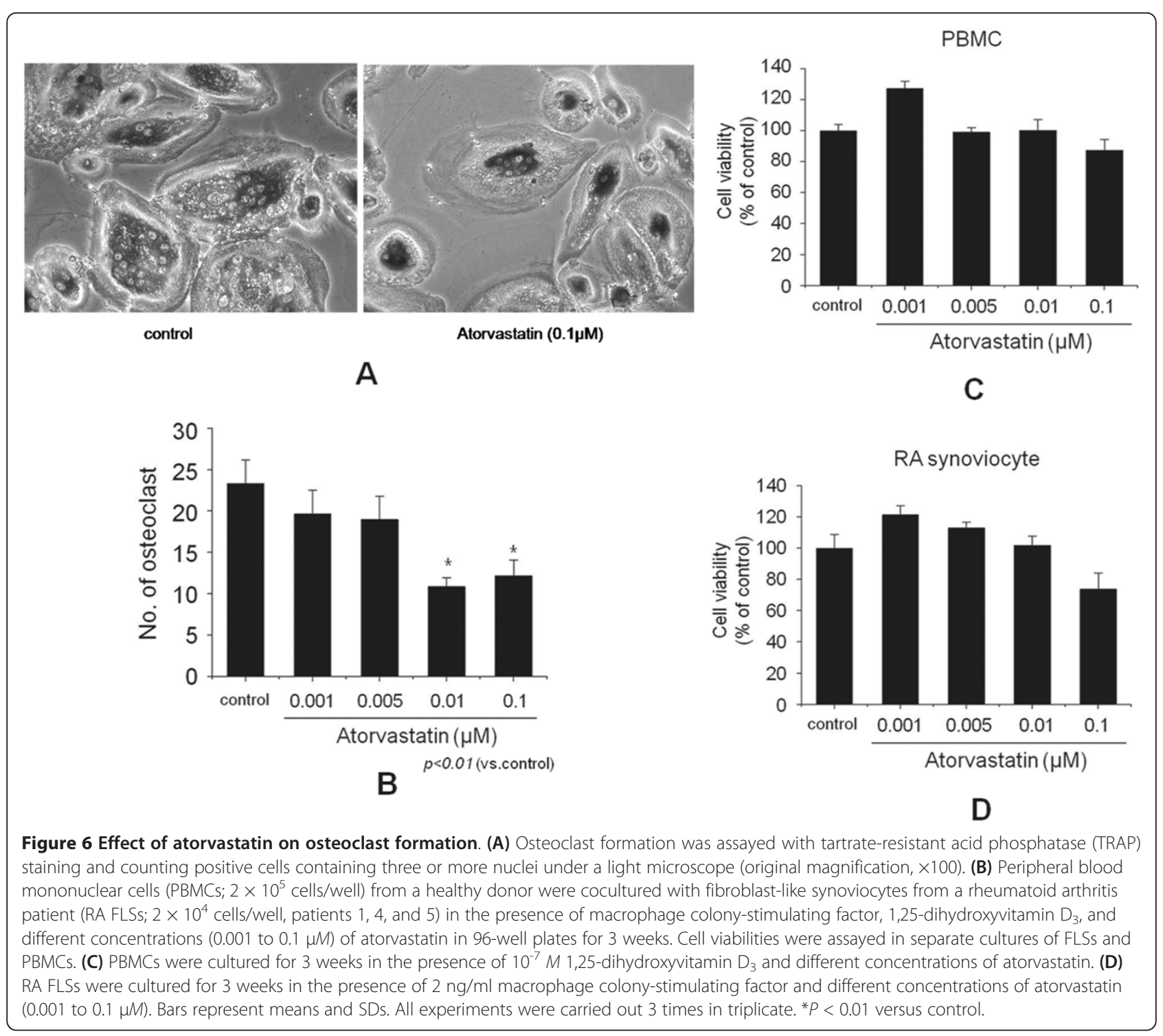

statins appear to have beneficial therapeutic effects on several human diseases, such as multiple sclerosis (MS) [22] and osteoporosis [23], which have no direct association with cholesterol levels. Recently, a number of reports have been issued on the antiinflammatory potentials of statins in rheumatic disease $[18,19,24,25]$ Therefore, we hypothesized that atorvastatin could have beneficial effects on the progressive joint destruction in RA.

In a preliminary study, we confirmed that TNF- $\alpha$ induced RANKL in FLSs from RA patients after incubation for 24 hours, which is consistent with that found by Kubota et al. [26]. In the present study, we found that atorvastatin inhibited the expression of TNF- $\alpha$-induced RANKL in FLSs from RA patients. Simvastatin also significantly and dose-dependently inhibited the expression of RANKL mRNA and protein in the FLSs of RA patients.
Mevalonate not only is a substrate for cholesterol biosynthesis, but also is required for the synthesis of several other biologically important lipid intermediates by means of an alternative synthesis pathway [27]. Furthermore, it is well known that mevalonate prevents the effects of statins, and in the present study, we found that the suppression of RANKL expression by statins is prevented by mevalonate. Osteoclasts play an important role in rheumatoid bone erosion in RA [28-30], and RANKL plays an important role in differentiation of osteoclasts from their precursor cells and promotes the activity and survival of these cells, which leads to bone resorption [31]. In the present study, the results were obtained by using a coculture system for osteoclastogenesis and showed that atorvastatin inhibits osteoclast formation. To our knowledge, this is the first report describing that atorvastatin inhibits osteoclastogenesis by attenuating RANKL expression in the FLSs of RA. 
In the present study, we performed cocultures at lower atorvastatin concentrations $(0.001$ to $0.1 \mu M)$. Exposure to higher concentrations ( $1 \mu M$ or more) for 3 weeks was found to be toxic to both FLSs and PBMCs (data not shown).

The receptor activator of the NF- $\kappa \mathrm{B}$ (RANK)/RANKL system has been shown to be a critical factor during osteoclast differentiation and bone resorption [31-33]. In addition, osteoprotegerin (OPG) functions as a high-affinity soluble decoy receptor for RANKL and competes with RANK for RANKL binding. Therefore, OPG is an effective inhibitor of the RANK-RANKL interaction. Several research groups have assessed the role of the RANK/RANKL/OPG system in RA, and experimental arthritis models have been established to study the in vivo effects of these molecules [4]. Recently, RANKL was reported to participate in osteoclast formation in a model of spontaneously developing erosive arthritis in the mouse [30]. However, in the present study, atorvastatin did not enhance the expressions of OPG protein and mRNA, and atorvastatin did not affect RANK expression in $\mathrm{CD} 14^{+}$cells. These findings indicate that the inhibition of osteoclast formation by atorvastatin is independent of OPG and RANK.

Signaling pathways that regulate proinflammatory mediator expression in FLSs of RA patients include MAPKs and NF- $\kappa$ B. Three MAPK families have been implicated in RA: ERK1/2, JNK, and p38 MAPK [34]. Interestingly, all three of these MAPK families are activated in RA synovial tissue and in cultured FLSs from RA patients. Furthermore, TNF- $\alpha$ has the potential to signal through all three [35]. However, we observed that atorvastatin decreased the phosphorylation of p38 but not that of ERK 1/2 or JNK, and that SB203580 (a specific p38 inhibitor) had a similar inhibitory effect on RANKL production in the FLSs of RA patients. Therefore, p38 may play a central role in which atorvastatin suppresses the expression of RANKL by TNF- $\alpha$.

\section{Conclusions}

The present study shows that atorvastatin markedly reduce RANKL expression in the fibroblast-like synoviocytes of rheumatoid arthritis patients, and atorvastatin inhibits osteoclastogenesis in co-cultures of PBMCs and FLSs. These results suggest that atorvastatin may inhibit osteoclastogenesis and bone destruction in RA patients.

\section{Additional material}

Additional file 1: Figure S1. Effects of simvastatin on receptor activator of nuclear factor $\kappa \mathrm{B}$ ligand (RANKL) expression in fibroblast-like synoviocytes (FLSs) from rheumatoid arthritis (RA) patients (patients 1, 2, and 3). FLSs were isolated from three RA patients and cultured in the presence of TNF- $\alpha(20 \mathrm{ng} / \mathrm{ml})$ with or without simvastatin $(10$ to $100 \mu M)$ for 24 hours. RANKL expressions were analyzed with RT-PCR (A) and Western blotting (B).

Additional file 2: Figure S2. Effects of mevalonate on the statininduced suppression of RANKL. FLSs from RA patients (patients 1, 2, and 3) were cultured in the presence of TNF- $\alpha(20 \mathrm{ng} / \mathrm{ml})$, and then simvastatin (50 to $100 \mu \mathrm{M})$ and mevalonate $(100 \mu \mathrm{M})$ were added for 24 hours. RANKL expressions were analyzed with RT-PCR (A) and Western blotting (B).

Additional file 3: Figure S3. The effects of simvastatin on cell viability and apoptosis. (A) Effects of simvastatin on the viability of FLSs from an RA patient (patients 1, 2, and 3). Cells were cultured for 24 hours in the presence of TNF- $\alpha(20 \mathrm{ng} / \mathrm{ml})$ and simvastatin at different concentrations (10 to $100 \mu \mathrm{M}$ ). Cell viabilities were determined by using MTT assays. (B) Effects of simvastatin on the apoptosis of FLSs, as determined by propidium iodide staining.

\section{Abbreviations}

DMEM-HG: Dulbecco Modified Eagle Medium-High Glucose; dNTP: deoxynucleotide triphosphate; DTT: dithiothreitol; ELISA: enzyme-linked immunosorbent assay; FLS: fibroblast-like synoviocyte; GAPDH: glyceraldehyde 3-phosphate dehydrogenase; HMG-COA: hydroxymethylglutaryl-coenzyme A; MAPK: mitogen-activated protein kinase; M-CSF: macrophage colony-stimulating factor; MTT: methylthiazol tetrazolium; OPG: osteoprotegerin; PBMC: peripheral blood mononuclear cell; PBS: phosphate-buffered saline; PI staining: propidium iodide staining; RA: rheumatoid arthritis; RANK: receptor activator of nuclear factor; RANKL: receptor activator of nuclear factor $\mathrm{KB}$ ligand; RT-PCR: reverse transcriptionpolymerase chain reaction; TNF-a: tumor necrosis factor a; TRAP: tartrateresistant acid phosphatase.

\section{Acknowledgements}

This work was supported by the R\&D Program of MKE/KEIT (10035615) and by a grant of the Korea Healthcare technology R\&D Project, Ministry of Health and Welfare, Republic of Korea (A102065) and grant R31-2012-00010103-0 from the World Class University program of the MEST and the NRF.

\section{Author details}

'Division of Rheumatology, Department of Internal Medicine, Seoul National University Hospital, 101 Daehak-ro, Jongno-gu, Seoul, 110-744, Korea. ${ }^{2}$ Division of Rheumatology, Department of Internal Medicine, Seoul National University Bundang Hospital, 82, Gumi-ro 173 Beon-gil, Bundang-gu, Seongnam-si, Gyeonggi-do, 463-707, Korea. ${ }^{3}$ WCU Department of Molecular Medicine and Biopharmaceutical Sciences, Medical Research Institute, Seoul National University College of Medicine, 103 Daehak-ro, Jongno-gu, Seoul, 110-799, Korea.

\section{Authors' contributions}

YWS was responsible for designing the study, access to samples, and manuscript preparation. JYK designed the study and performed most of the experiments, data analysis, and wrote the manuscript. EYL was responsible for designing the study and osteoclast experiments. EBL, YJL, and HJY contributed to the conception of the study and interpretation of the data. JYC performed qRT-PCR. All authors read and approved the final manuscript.

\section{Competing interests}

The authors declare that they have no competing interests.

Received: 25 June 2011 Revised: 6 July 2011 Accepted: 17 August 2012 Published: 17 August 2012

\section{References}

1. Yasuda H, Shima N, Nakagawa N, Yamaguchi K, Kinosaki M, Mochizuki S, Tomoyasu A, Yano K, Goto M, Murakami A, Tsuda E, Morinaga T, Higashio K, Udagawa N, Takahashi N, Suda T: Osteoclast differentiation factor is a ligand for osteoprotegerin/osteoclastogenesis-inhibitory factor and is identical to TRANCE/RANKL. Proc Natl Acad Sci USA 1998, 95:3597-3602. 
2. Kong YY, Yoshida H, Sarosi I, Tan HL, Timms E, Capparelli C, Morony S, Oliveira-dos-Santos AJ, Van G, Itie A, Khoo W, Wakeham A, Dunstan CR, Lacey DL, Mak TW, Boyle WJ, Penninger JM: OPGL is a key regulator of osteoclastogenesis, lymphocyte development and lymph-node organogenesis. Nature 1999, 397:315-323.

3. Lee CK, Lee EY, Chung SM, Mun SH, Yoo B, Moon HB: Effects of diseasemodifying antirheumatic drugs and antiinflammatory cytokines on human osteoclastogenesis through interaction with receptor activator of nuclear factor kappaB, osteoprotegerin, and receptor activator of nuclear factor kappaB ligand. Arthritis Rheum 2004, 50:3831-3843.

4. Neumann E, Gay S, Muller-Ladner U: The RANK/RANKL/osteoprotegerin system in rheumatoid arthritis: new insights from animal models. Arthritis Rheum 2005, 52:2960-2967.

5. Gravallese EM: Bone destruction in arthritis. Ann Rheum Dis 2002, 61(Suppl 2):ii84-ii86.

6. Ziolkowska M, Kurowska M, Radzikowska A, Luszczykiewicz G, Wiland P, Dziewczopolski W, Filipowicz-Sosnowska A, Pazdur J, Szechinski J, Kowalczewski J, Rell-Bakalarska M, Maslinski W: High levels of osteoprotegerin and soluble receptor activator of nuclear factor kappa B ligand in serum of rheumatoid arthritis patients and their normalization after anti-tumor necrosis factor alpha treatment. Arthritis Rheum 2002, 46:1744-1753.

7. Haynes DR, Crotti TN, Loric M, Bain Gl, Atkins GJ, Findlay DM: Osteoprotegerin and receptor activator of nuclear factor kappaB ligand (RANKL) regulate osteoclast formation by cells in the human rheumatoid arthritic joint. Rheumatology (Oxford) 2001, 40:623-630.

8. Takayanagi H, lizuka H, Juji T, Nakagawa T, Yamamoto A, Miyazaki T, Koshihara Y, Oda H, Nakamura K, Tanaka S: Involvement of receptor activator of nuclear factor kappaB ligand/osteoclast differentiation factor in osteoclastogenesis from synoviocytes in rheumatoid arthritis. Arthritis Rheum 2000, 43:259-269.

9. Redlich K, Hayer S, Ricci R, David JP, Tohidast-Akrad M, Kollias G, Steiner G, Smolen JS, Wagner EF, Schett G: Osteoclasts are essential for TNF-alphamediated joint destruction. J Clin Invest 2002, 110:1419-1427.

10. Takayanagi $\mathrm{H}$ : Inflammatory bone destruction and osteoimmunology. J Periodont Res 2005, 40:287-293.

11. Hebert PR, Gaziano JM, Chan KS, Hennekens CH: Cholesterol lowering with statin drugs, risk of stroke, and total mortality: an overview of randomized trials. JAMA 1997, 278:313-321.

12. Pedersen TR: Statin trials and goals of cholesterol-lowering therapy after AMI. Am Heart J 1999, 138:S177-S182.

13. Takemoto M, Liao JK: Pleiotropic effects of 3-hydroxy-3-methylglutaryl coenzyme a reductase inhibitors. Arterioscler Thromb Vasc Biol 2001, 21:1712-1719.

14. Wierzbicki AS, Poston R, Ferro A: The lipid and non-lipid effects of statins. Pharmacol Ther 2003, 99:95-112.

15. McCarey DW, Mclnnes IB, Madhok R, Hampson R, Scherbakov O, Ford I, Capell HA, Sattar N: Trial of Atorvastatin in Rheumatoid Arthritis (TARA): double-blind, randomised placebo-controlled trial. Lancet 2004, 363:2015-2021.

16. Mach F: Statins as immunomodulatory agents. Circulation 2004, 109(21 Suppl 1):|115-|I17.

17. Kwak BR, Mulhaupt F, Mach F: Atherosclerosis: anti-inflammatory and immunomodulatory activities of statins. Autoimmun Rev 2003, 2:332-338.

18. Abud-Mendoza C, de la Fuente H, Cuevas-Orta E, Baranda L, Cruz-Rizo J, Gonzalez-Amaro R: Therapy with statins in patients with refractory rheumatic diseases: a preliminary study. Lupus 2003, 12:607-611.

19. El-Barbary AM, Hussein MS, Rageh EM, Hamouda HE, Wagih AA, Ismail RG: Effect of atorvastatin on inflammation and modification of vascular risk factors in rheumatoid arthritis. J Rheumatol 2011, 38:229-235.

20. Aletaha D, Neogi T, Silman AJ, Funovits J, Felson DT, Bingham CO, Birnbaum NS, Burmester GR, Bykerk VP, Cohen MD, Combe B, Costenbader KH, Dougados M, Emery P, Ferraccioli G, Hazes JM, Hobbs K, Huizinga TW, Kavanaugh A, Kay J, Kvien TK, Laing T, Mease P, Ménard HA, Moreland LW, Naden RL, Pincus T, Smolen JS, Stanislawska-Biernat E Symmons D, et al: 2010 Rheumatoid arthritis classification criteria: an American College of Rheumatology/European League Against Rheumatism collaborative initiative. Arthritis Rheum 2010, 62:2569-2581.

21. Takai Y, Sasaki T, Matozaki T: Small GTP-binding proteins. Physiol Rev 2001, 81:153-208.
22. Vollmer T, Key L, Durkalski V, Tyor W, Corboy J, Markovic-Plese S, Preiningerova J, Rizzo M, Singh I: Oral simvastatin treatment in relapsingremitting multiple sclerosis. Lancet 2004, 363:1607-1608.

23. Hatzigeorgiou C, Jackson JL: Hydroxymethylglutaryl-coenzyme A reductase inhibitors and osteoporosis: a meta-analysis. Osteoporos Int 2005, 16:990-998.

24. Leung BP, Sattar N, Crilly A, Prach M, McCarey DW, Payne H, Madhok R, Campbell C, Gracie JA, Liew FY, Mclnnes IB: A novel anti-inflammatory role for simvastatin in inflammatory arthritis. J Immunol 2003, 170:1524-1530.

25. Abeles AM, Pillinger MH: Statins as antiinflammatory and immunomodulatory agents: a future in rheumatologic therapy? Arthritis Rheum 2006, 54:393-407

26. Kubota A, Hasegawa K, Suguro T, Koshihara Y: Tumor necrosis factor-alpha promotes the expression of osteoprotegerin in rheumatoid synovial fibroblasts. J Rheumatol 2004, 31:426-435.

27. Cohen LH, Pieterman E, van Leeuwen RE, Overhand M, Burm BE, van de Marel GA, van Boom JH: Inhibitors of prenylation of Ras and other Gproteins and their application as therapeutics. Biochem Pharmacol 2000, 60:1061-1068.

28. Gravallese EM, Manning C, Tsay A, Naito A, Pan C, Amento E, Goldring SR: Synovial tissue in rheumatoid arthritis is a source of osteoclast differentiation factor. Arthritis Rheum 2000, 43:250-258.

29. Fujikawa Y, Sabokbar A, Neale S, Athanasou NA: Human osteoclast formation and bone resorption by monocytes and synovial macrophages in rheumatoid arthritis. Ann Rheum Dis 1996, 55:816-822.

30. Wu Y, Liu J, Feng X, Yang P, Xu X, Hsu HC, Mountz JD: Synovial fibroblasts promote osteoclast formation by RANKL in a novel model of spontaneous erosive arthritis. Arthritis Rheum 2005, 52:3257-3268.

31. Lacey DL, Timms E, Tan HL, Kelley MJ, Dunstan CR, Burgess T, Elliott R, Colombero A, Elliott G, Scully S, Hsu H, Sullivan J, Hawkins N, Davy E, Capparelli C, Eli A, Qian YX, Kaufman S, Sarosi I, Shalhoub V, Senaldi G, Guo J, Delaney J, Boyle WJ: Osteoprotegerin ligand is a cytokine that regulates osteoclast differentiation and activation. Cell 1998, 93:165-176.

32. Anderson DM, Maraskovsky E, Billingsley WL, Dougall WC, Tometsko ME, Roux ER, Teepe MC, DuBose RF, Cosman D, Galibert L: A homologue of the TNF receptor and its ligand enhance T-cell growth and dendritic-cell function. Nature 1997, 390:175-179.

33. Wong BR, Rho J, Arron J, Robinson E, Orlinick J, Chao M, Kalachikov S, Cayani E, Bartlett FS, Frankel WN, Lee SY, Choi Y: TRANCE is a novel ligand of the tumor necrosis factor receptor family that activates c-Jun Nterminal kinase in T cells. J Biol Chem 1997, 272:25190-25194.

34. Schett G, Tohidast-Akrad M, Smolen JS, Schmid BJ, Steiner CW, Bitzan P, Zenz P, Redlich K, Xu Q, Steiner G: Activation, differential localization, and regulation of the stress-activated protein kinases, extracellular signalregulated kinase, c-JUN N-terminal kinase, and p38 mitogen-activated protein kinase, in synovial tissue and cells in rheumatoid arthritis. Arthritis Rheum 2000, 43:2501-2512.

35. Fujisawa K, Aono H, Hasunuma T, Yamamoto K, Mita S, Nishioka K: Activation of transcription factor NF-kappa B in human synovial cells in response to tumor necrosis factor alpha. Arthritis Rheum 1996, 39:197-203.

\section{doi:10.1186/ar4018}

Cite this article as: Kim et al:: Atorvastatin inhibits osteoclastogenesis by decreasing the expression of RANKL in the synoviocytes of rheumatoid arthritis. Arthritis Research \& Therapy 2012 14:R187.

\section{Submit your next manuscript to BioMed Central and take full advantage of:}

- Convenient online submission

- Thorough peer review

- No space constraints or color figure charges

- Immediate publication on acceptance

- Inclusion in PubMed, CAS, Scopus and Google Scholar

- Research which is freely available for redistribution

Submit your manuscript at www biomedcentral com/submit
C Biomed Central 